\title{
Pengembangan Sistem Informasi Tukar Barang Untuk Pemanfaatan Barang Tidak Terpakai dengan Flutter Framework.
}

\author{
http://dx.doi.org/10.28932/jutisi.v6i3.3071
}

\author{
Sulaeman Santoso ${ }^{\bowtie 1}$, Daniel Jahja Surjawan ${ }^{* 2}$, Erico Darmawan Handoyo ${ }^{\# 3}$ \\ \#S1 Teknik Informatika,Universitas Kristen Maranatha \\ Jl. Prof. Drg. Suria Sumantri No. 65, Bandung \\ ${ }^{1}$ sulaeman. santosodit.maranatha.edu \\ ${ }^{3}$ erico.dheit.maranatha.edu \\ * S1 Teknik Informatika,Universitas Kristen Maranatha \\ Jl. Prof. Drg. Suria Sumantri No. 65, Bandung \\ ${ }^{2}$ daniel.jseit.maranatha.edu
}

\begin{abstract}
Humans in general cannot be separated from the consumptive lifestyle. Problems related to ownership of goods that are no longer in use are increasing. These items are stored and never used again by the owner. Most of these items do not have high sales value because of the condition of used goods or for some people the goods are unused. The item can be valuable in the hands of those who need it. The problem occurs when information on the unused item does not reach the person in need. This research attempt to develop an exchanging unused goods system without a payment process. Each item will be worth one token, this is done to prevent system exploitation, this differentiates the proposed system with another bartering system. Furthermore, the system was developed to be a portal in providing information and facilitating people who will barter their goods that are not used. The process of giving and taking goods will be done separately.
\end{abstract}

Keywords-Barter System; Portal; Token; Trade; Waste Management; Website

\section{Pendahuluan}

Saat ini manusia pada umumnya tidak bisa terlepas dari gaya hidup konsumtif. Permasalahan terkait kepemilikan barang yang tidak lagi digunakan pun kian meningkat. Barang-barang ini tersimpan dan tidak pernah digunakan lagi oleh pemiliknya. Kebanyakan dari barang tersebut bila dijual tidak memiliki nilai jual yang tinggi karena kondisi barang bekas ataupun untuk beberapa orang barang tersebut tidak ada gunanya. Barang tersebut bisa menjadi bernilai di tangan orang-orang yang membutuhkannya. Masalah terjadi saat informasi terhadap barang yang tidak terpakai tersebut tidak sampai ke orang yang membutuhkan. Oleh sebab itu dilakukan penelitian untuk mengatasi masalah ini dengan menggunakan sebuah sistem barter secara online.
Sistem barter sendiri sudah muncul sejak 6000 sebelum masehi di Mesopotamia [1]. Dan sistem barter online sendiri juga telah ada dalam berbagai tipe. Namun Sistem barter yang tersedia seperti juga sistem barter tradisional membutuhkan dua pihak yang saling bersepakat menukarkan barangnya. Namun hal ini sulit untuk ditemukan sehingga mengurangi tingkat keberhasilan transaksi barter. Beberapa situs mencoba mengatasi persoalan ini dengan menambahkan unsur moneter ke dalam transaksi barter. Kendala utama terdapat pada penentuan nilai finansial dari barang yang rusak ataupun bekas secara objektif. Sistem usulan akan mencoba mengatasi persoalan ini dengan menggunakan sistem token yang tidak memiliki nilai moneter.

Dengan sistem token ini, setiap pertukaran barang akan bernilai satu token. Apabila pengguna menukarkan atau mengambil barang, maka pengguna tersebut akan mendapat atau memberikan token. Token ini tidak bernilai uang untuk mencegah penyalahgunaan situs menjadi tempat jual beli. Setiap barang juga diberikan harga yang sama untuk mencegah terjadinya eksploitasi sistem. Diharapkan dengan dengan menggunakan token, pertukaran barang dapat terjadi dengan lebih sukarela dan aktif.

\section{KAJIAN TEORI}

Di dalam penelitian ini, terdapat beberapa teori yang dijadikan landasan dalam penelitian ini. Berikut ini adalah teori-teori yang digunakan:

\section{A. Sistem Barter Online}

Sistem barter adalah sistem ekonomi pertama yang tercatat di dalam sejarah bahkan hingga 6000 tahun sebelum masehi oleh bangsa mesopotamia [1]. Namun pada 
perkembangannya sistem ini digantikan oleh sistem uang yang menjadi alat tukar universal. Namun, sistem barter ini tetap ada hingga sekarang dalam bentuk tradisional maupun bentuk elektronik. beberapa hal yang menjadi kekurangan dari sistem barter baik traidisional maupun elektronik adalah:

- Kesulitan mencari penukar yang membutuhkan dan menyediakan barang yang tepat [2] [3]. Karena sistem barter traditional adalah sebuah pertukaran barang 1 ke 1 dimana penukar pertama harus mencari penukar kedua yang mau memberi barang yang ia butuhkan Dan menerima barang yang ia tawarkan. Hal ini disebut juga sebagai double coincidence of wants [4]

- Kesulitan kedua pada sistem barter traditional adalah kesulitan penentuan nilai dari barang yang hendak ditukar [3]. Seringkali tidak ada kesepakatan akan nilai barang hendak dtukar antara dua pihak. Walaupun ada kecocokan pada barang, seringkali terjadi ketidak cocokan pada nilai dari barang.

Beberapa website modern yang mengimplementasikan $e$ barter adalah sebagai berikut:

1. Craiglist: adalah sebuah website pertukaran barang

2. Free cycle: adalah website pertukaran barang yang berfokus pada orang memberikan barang

3. GameTradingZone Dan Goozex: adalah media pertukaran game digital

4. U-Exhange, Zwaggle adalah website pertukaran barang yang lain.

Beberapa penelitian yang membahas hal ini diantaranya adalah pembuatan sistem pertukaran barang bekas di aplikasi mobile oleh jiuyuan Huo et al [5] dan pada platform web oleh Zhang Hai-tao [6], Namun sistem sistem yang dikembangkan ini masih menggunakan konsep pertukaran satu ke satu.

Sejumlah layanan barter online yang tersedia umumnya memiliki konsep pertukaran satu dengan satu sehingga tetap menimbulkan masalah dalam pertukaran barang, yaitu bahwa seorang penukar barang harus terlebih dahulu mencari orang lain yang menghendaki barang milikinya dan sebaliknya.

Masalah formal pertukaran barang ini telah di bahas pada penelitian yang di lakukan oleh beberapa peneliti [5] dan menghasilkan sistem barter bertingkat dengan hierarki. Usaha untuk menggunakan agent cerdas untuk mengatasi masalah pencarian juga telah dilakukan salah satunya di tahun 2017 dengan BDI-Agent (Belief-Desire-Intention) [3]. Salah satu cara lain mengatasi masalah pencarian adalah dengan memodelkan pencarian sebagai graph dan mencari circular cycle yang tepat pada exchange graph [6].

Penelitian ini akan mencoba memberikan jawaban yang berbeda terhadap permasalahan yang dihadapi oleh sistem barter online. Pada umumnya, layanan barter online yang ada saat ini masih memiliki kendala terkait doubleconincidence-of-wants problem dan monetary problem. Sistem usulan yang diteliti Akan mencoba mengatasi Hal tersebut dengan menggunakan sistem token yang bernilai sama (uniform).

Setiap pengguna sistem ini akan menerima satu buah token pengambilan di awal. Dan baru mendapatkan token kembali apabila telah berhasil memberikan barang ke orang lain. Untuk menghindari keperluan mencari orang yang tepat, Maka penukaran barang akan dilakukan secara terpisah. EKetika seseorang mengambil barang ia akan mengkonsumsi satu buah token dan ketka seseorang berhasil memberikan barang (diambil oleh orang lain) maka ia akan menerima satu buah token.

Penggunaan uang sebagai alat penukaran memiliki kegunaanya tersendiri, namun dalam kasus penukaran barang, banyak usaha untuk menggunakan alat penukar pengganti dari uang [4] namun pada akhirnya tetap beroperasi seperti medium penukar yang memiliki nilai. Namun, dengan sistem token, nilai semua barang yang ditukarkan akan bernilai sama. Sehingga user bebas menentukan hendak menukarkan barang apapun yang bernilai satu token. Hal ini di lakukan untuk mengatasi masalah pencarian Dan juga mencegah eksploitasi sistem penentuan nilai tetap juga di lakukan untuk mencegah situs berubah menjadi marketplace digital.

Hal ini tentu saja menimbulkan masalah nilai yang tidak seragam dari barang yang hendak ditukarkan. Namun tujuan utama dari situs yang hendak dikembangkan adalah ke arah pertukaran barang yang memang dinilai tidak memiliki nilai cukup berharga atau sulit untuk dijual. Sehingga diharapkan hal ini tidak menjadi halangan tapi menjadi dorongan. Dengan sistem ini diharapkan barang barang tak terpakai dapat diberikan kepada orang yang membutuhkan dan menimbulkan budaya memberi di kalangan masyarakat.

\section{B. Multiplatform Application}

Sistem usulan Akan dikembangkan dalam bentuk yang mudah untuk digunakan masyarakat saat ini. Karena pada saat ini platform aplikasi yang digunakan masyarakat sangat bervariasi Maka pada sistem usulan akan menggunakan perangkat lunak yang multiplatform. Disini beberapa platform yang dapat ditarget oleh pengembangan aplikasi ini adalah web, android, dan ios. Ini semua dimungkinkan dengan menggunakan framework multiplatform flutter.

\section{Web Service}

Penggunaan web service sebagai penyedia informasi sangatlah penting dalam sebuah aplikasi multiplatform karena ia bertindak sebagai penyedia resource. Penggunaan web service juga memiliki added value yaitu memisahkan business logic pada server dan tampilan atau antarmuka pada aplikasi pengguna. Penelitian ini akan dikembangkan dengan menggunakan web service yang terpisah untuk menjamin skalabilitas dari sistem. Web service ini akan dikembangkan dalam pola MVC sesuai dengan framework yang akan digunakan yaitu Laravel. 


\section{Flutter framework}

Flutter adalah sebuah framework multiplatform yang dikembangkan oleh tim di Google [7]. Flutter bertujuan untuk menyederhanakan pengembangan perangkat lunak multiplatform dengan satu code base. Hal ini juga berlaku untuk pemisahan UI dan code yang biasa terdapat pada bahsa bahasa pengembangan yang lain. Flutter membuat satu codebase yang cukup untuk UI dan logic.

Flutter mengimplementasikan kodenya dengan widget. Widget di dalam flutter dapat berupa komponen visual maupun sekedar penampung bagi widget yang lainnya. Dengan demikian, flutter memiliki kode yang bersifat hierarki. Error! Reference source not found. menunjukkan contoh kode pada flutter.

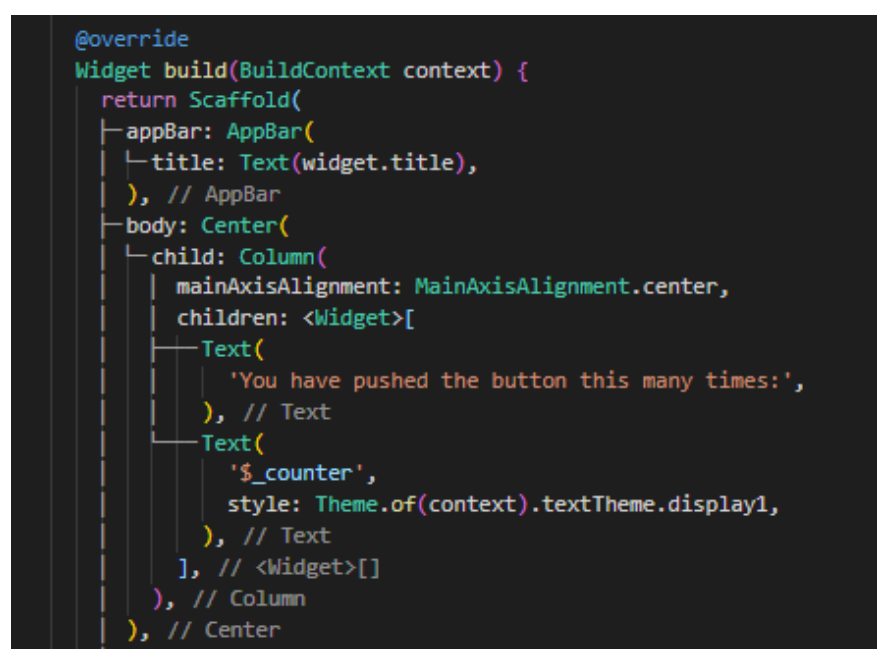

Gambar 1. Contoh Kode Pada Flutter

Yang menjadi pembeda antara flutter dengan solusi multiplatform yang lain adalah karena flutter tidak menggunakan penyambung seperti pendekatan multiplatform yang lain. Gambar 2 menunjukkan gambaran besar dari pendekatan flutter terhadap solusi multiplatform Dengan struktur ini perubahan platform tidak akan menggangu kinerja dari aplikasi. Dan tidak ada jembatan yang berpotensi menjadi bottleneck.

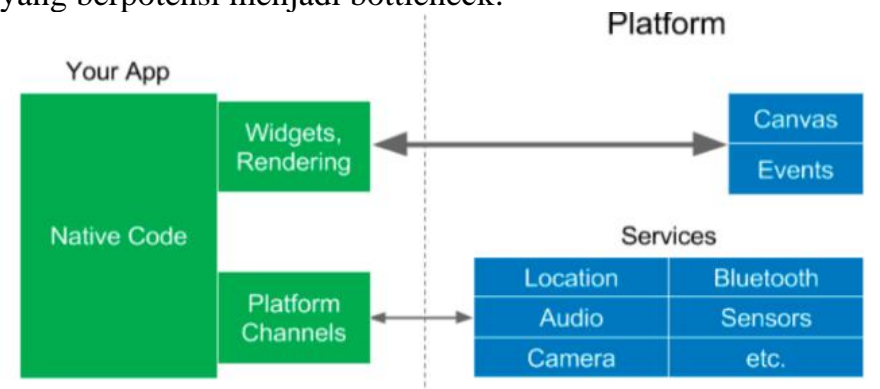

Gambar 2. Struktur Arsitektur Flutter [8]

\section{E. Laravel Framework}

Laravel framework adalah sebuah framework PHP [9] . Laravel digunakan pada penelitian ini untuk menyediakan web service. Sesuai dengan konsep pengembangannya Laravel menerapkan konsep MVC (Model, View, Controller) di dalam pengembangan perangkat lunaknya, dalam artian setiap code pada web service sudah dibagi menjadi model untuk penyimpanan data, view untuk menampilkan data (tidak digunakan pada web service), dan Controller yang digunakan untuk berinteraksi dengan data.

Laravel menggunakan pula konsep ORM (object relational mapping ) [10] dimana setiap data pada tabel di database dipetakan pada sebuah object pada bahasa pemrogaman. Laravel juga menggunakan syntax eloquent untuk mempermudah manipulasi data tanpa perlu menggunakan query SQL seperti pada umumnya dilakukan pada sebuah aplikasi database. Contoh dari syntax eloquent dapat dilihat pada Gambar 3.

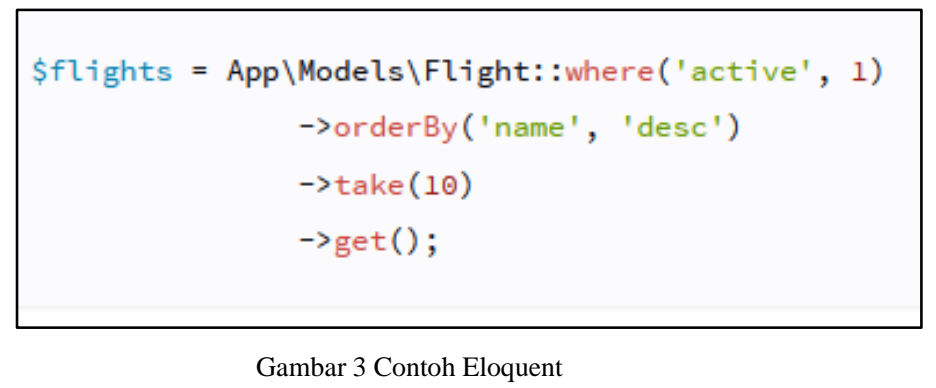

Laravel juga menyediakan konsep routing, dimana semua routing pada webservice dicatat dalam file terpisah yang menyatukan semua routing pada webservice. Rute webservice juga dibagi menjadi dua untuk web dan API. Karena disini laravel digunakan hanya sebagai web service maka semua rute akan dipasangkan pada file api. Contoh route pada laravel dapat dilhat pada Gambar 4.

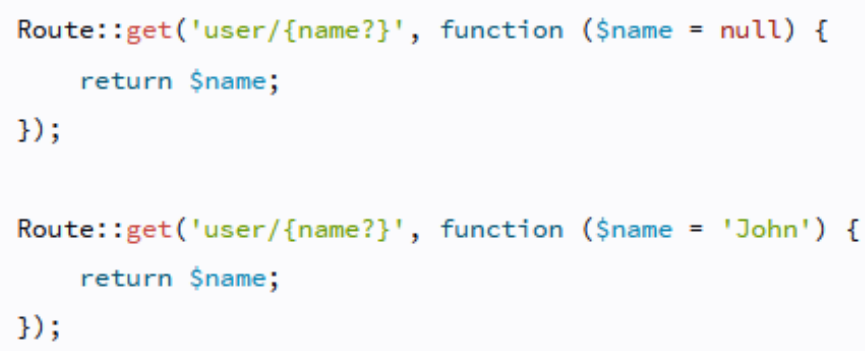

Gambar 4 Routing pada Laravel 


\section{ANALISIS DAN RANCANGAN SISTEM}

\section{F. Analisis Kebutuhan}

Sistem yang dikembangkan memerlukan sebuah cara untuk pertukaran barang yang asynchronous. Maksudnya adalah bahwa si penukar dan penerima barang tidak perlu melakukan pertukaran secara sekaligus dan dalam tempat yang sama. Oleh sebab itu dikembangkanlah sebuah sistem pertukaran yang ditunjukkan pada Gambar 5.

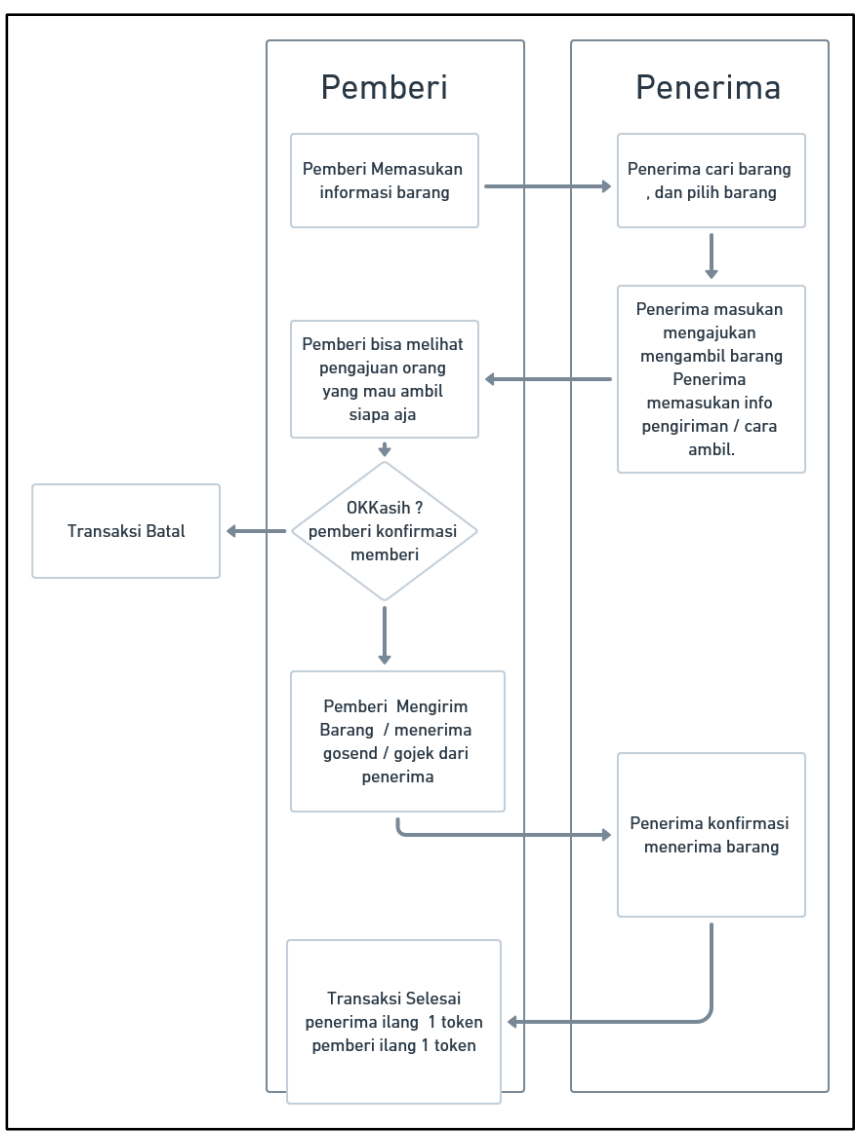

Gambar 5. Alur pertukaran gambar

1. Pertukaran barang dimulai dengan pemberi mengunggah barang pada sistem beserta informasi yang berkaitan dengan barang tersebut.

2. Potential penerima mencari barang dan memilih barang yang ia butuhkan. Lalu meminta barang yang ia butuhkan ( satu barang dapat di minta lebih dari satu penerima)

3. Pemberi dapat melihat orang orang yang meminta barangnya lalu menentukan hendak memberikan barang tersebut ke mana. (Penerima yang disetujui akan mendapatkan notifikasi penerimaan sedangkan yang ditolak akan mendapatkan notifikasi penolakan)
4. Pemberi lalu mengirimkan barang kepada penerima melalui metode yang disetujui. Status barang berubah menjadi sedang dikitim.

5. Penerima apabila sudah menerima barang akan menekan tombol diterima. Dan transaksi akan selesai.

Walaupun pertukaran barang sudah memiliki alur yang jelas, terdapat beberapa kasus yang mungkin terjadi dan menggagalkan transaksi. Beberapanya adalah sebagai berikut :

1. Kegagalan di bidang penerima untuk menerima barang akan menggantungkan transaksi walaupun token tidak akan tertukar tanpa konfirmasi

2. Kegagalan pengiriman dapat terjadi.namun bila terjadi ini adalah tanggung jawab pihak ketiga dan pertukaran barang dapat dibatalkan pada sistem

3. Kegagalan di bidang pemberi untuk memilih pengguna untuk diberikan barang. Hal ini di minimalisir dengan memberikan notifikasi pada pihak pemberi.

Selain dari alur, Sebuah sistem token juga dianalisa untuk kebutuhan pertukaran barang. Kebutuhan token diperlukan dikarenakan beberapa hal :

1. Pemberi dapat menerima token sebagai ganti barang yang dia berikan dan dapat ditukarkan dengan barang lain yang ia butuhkan.

2. Penerima dapat memberikan token agar barang yang diterima mendapakan kompensasi yang sesuai.

3. Token tidak dibuat sebagai nilai yang sama (uniform untuk setiap transaksi ) untuk menghindari eksploitasi sistem dimana penerima dan pemberi bekerjasama untuk menghasilkan token.

\section{G. Metode Penelitian}

Metode penelitian yang digunakan dalam pembuatan sistem barter ini terbagi menjadi beberapa tahap, yaitu sebagai berikut:

1. Pembangunan database untuk data sistem inventarisasi barter.

a. Menganalisis dan membuat desain basis data yang digunakan untuk penelitian. Terdapat 7 entitas yang dibangun dalam pembuatan aplikasi ini yaitu category, item, log, photo, roles, uphoto, dan user. Masing-masing entitas dan atribut dijelaskan dalam ER diagram pada Gambar 6. 


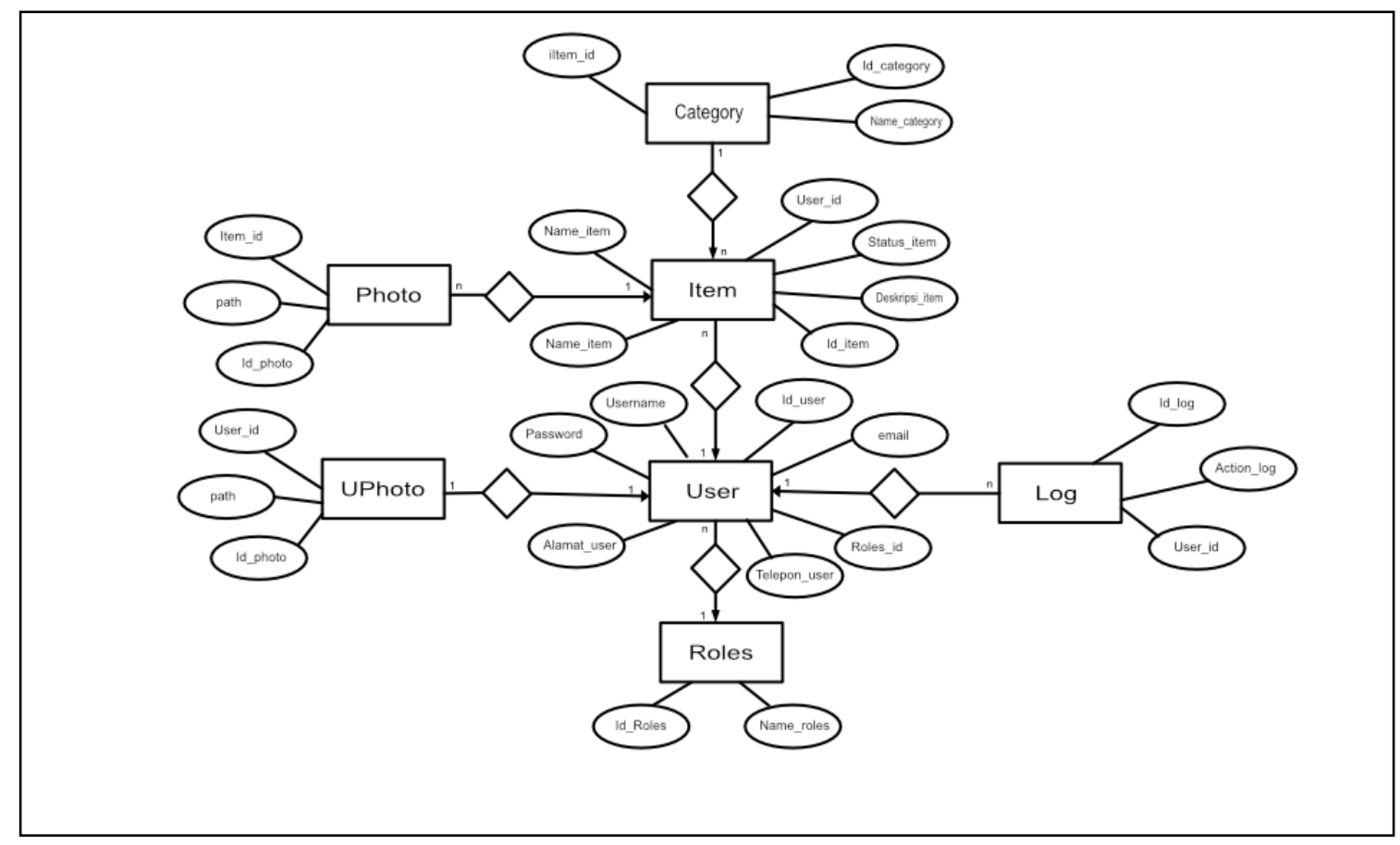

Gambar 6. Rancangan Basis Data

Tabel User digunakan untuk menyimpan data pengguna termasuk di dalamnya informasi pengiriman dan no kontak agar dapat dihubungi oleh pengunna lainnya.

Tabel Item menyimpan barang yang akan ditukarkan / diberikan kepada orang lain. Status item dibuat untuk menunjukkan status dari barang tersebut pada setiap tahap pertukaran barang.

Tabel Photo dan Uphoto adalah untuk menyimpan gambar photo untuk image dan user secara berurutan.

Tabel Log adalah untuk menyimpan segala perubahan yang terjadi oleh setiap user pada sistem sehingga perubahan dapat tercatat.

b. Mengembangkan web service yang akan digunakan untuk penelitian. Pengembangan dibuat berdasarkan entitas yang ada. Berikut ini adalah pengembangan API yang dibangun untuk aplikasi ayokasih.com.

i. Category

- DeleteCategory

- InsertCategory

- KeteranganDelete_UpdateCategory

ii. Item

- UpdateCategory

- DeleteItem

- InsertItem

- KeteranganDelete_UpdateItem
- UpdateItem

iii. $\log$

- DeleteLog

- InsertLog

iv. Photo

- KeteranganDelete_UpdateLog

- DeletePhoto

- InsertPhoto

- KeteranganDelete_UpdatePhoto

v. Roles

- DeleteRoles

- InsertRoles

- KeteranganDelete_UpdateRoles

- UpdateRoles

vi. UPhoto

- DeleteUPhoto

- InsertUPhoto

vii. User

- KeteranganDelete_UpdateUPhoto

- DeleteUser

- InsertUser

- KeteranganDelete_UpdateUser

- UpdateUser

2. Pembentukan aplikasi client

Analisa dan pengembangan aplikasi client crossplaform yang menggunakan web service yang telah dibuat.dalam kasus ini akan dikembangkan dua macam aplikasi client yaitu pada web dan mobile. Pada 
laporan perkembangan ini akan dijelaskan tampilan mobile terlebih dahulu.

\section{H. Tampilan Urutan Proses Dari Pengiriman dan Pengambilan}

Gambar 7 merupakan urut-urutan tampilan proses secara keseluruhan yang berjalan pada aplikasi mobile. Beberapa menu yang dapat diakses oleh pengguna yaitu: Registrasi, Login, Main, Profile, Histori, Setting, List Barang, Detil Barang, Pilih Barang, Pilih Penerima, dan Penerima Barang.

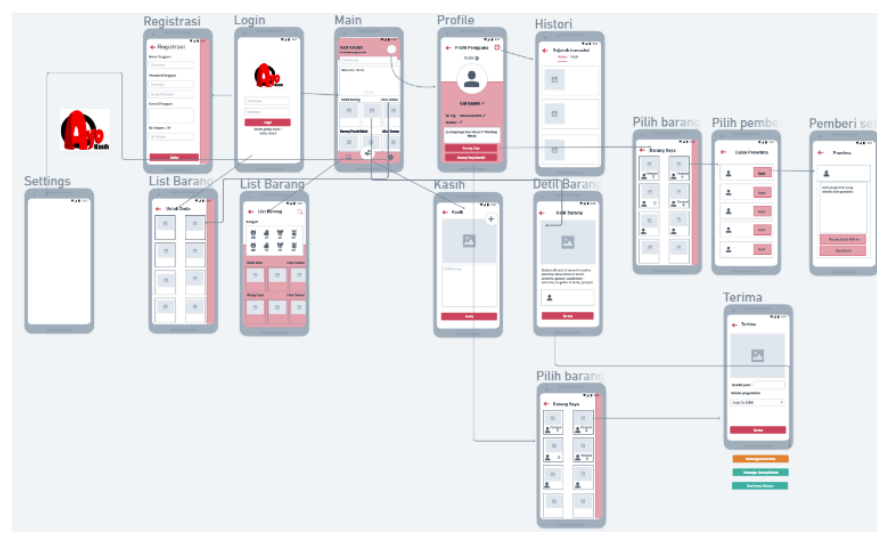

Gambar 7.Tampilan Urutan Proses

\section{IMPLEMENTASI}

Pada bagian ini akan dijelaskan masing-masing tampilan dari aplikasi mobile.

\section{A. Tampilan Registrasi Pengguna}

Gambar 8 adalah tampilan mobile dalam penelitian dan pembuatan sistem barter ayokasih.com:

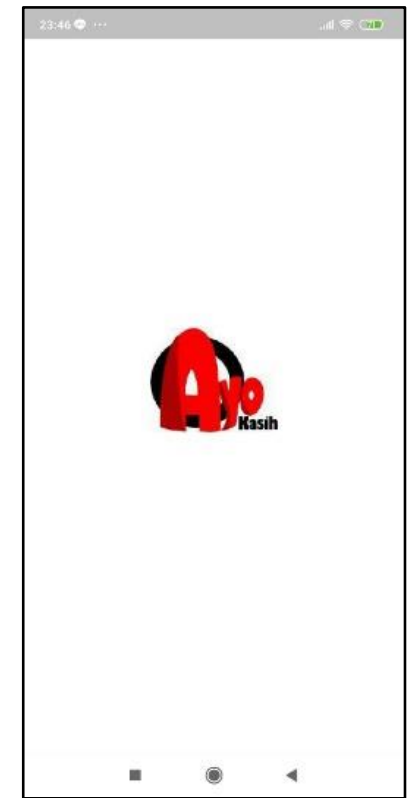

Gambar 8. Tampilan Memulai Aplikasi
Tampilan di atas akan muncul pertama kali saat pengguna meng-klik aplikasi. Selanjutnya pengguna akan diarahkan ke tampilan login pada gambar 9.

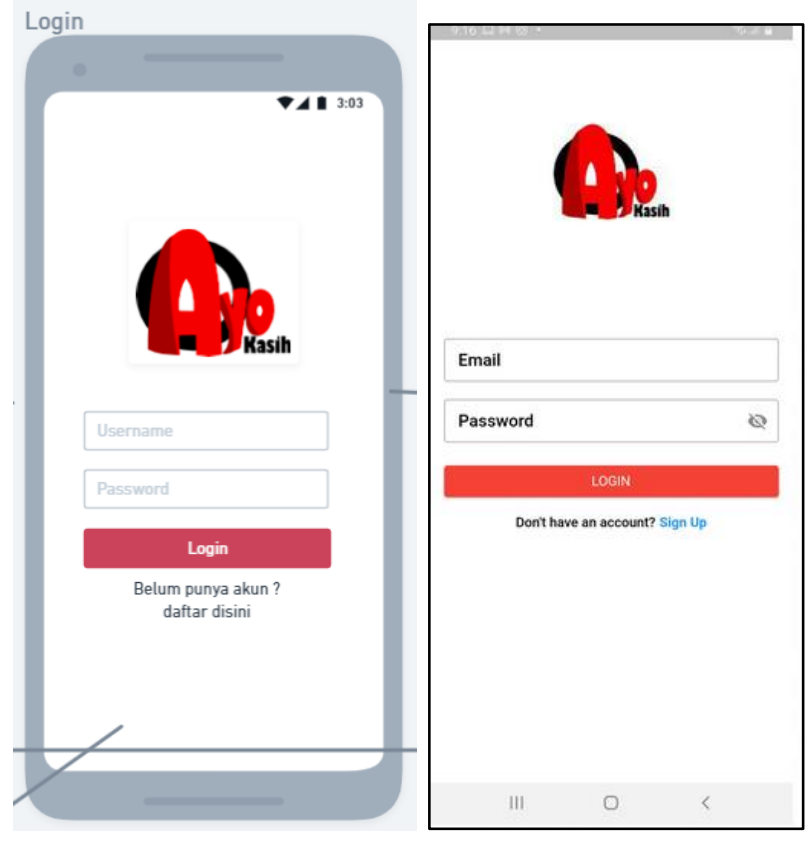

Gambar 9. Halaman Login

Pada halaman ini pengguna dipastikan sudah memiliki akun dengan memasukkan username dan password yang sudah dimiliki. Apabila belum memiliki aku, pengguna bisa klik Daftar Disini. Kemudian pengguna akan diarahkan pada tampilan register seperti tampilan pada Gambar 10.

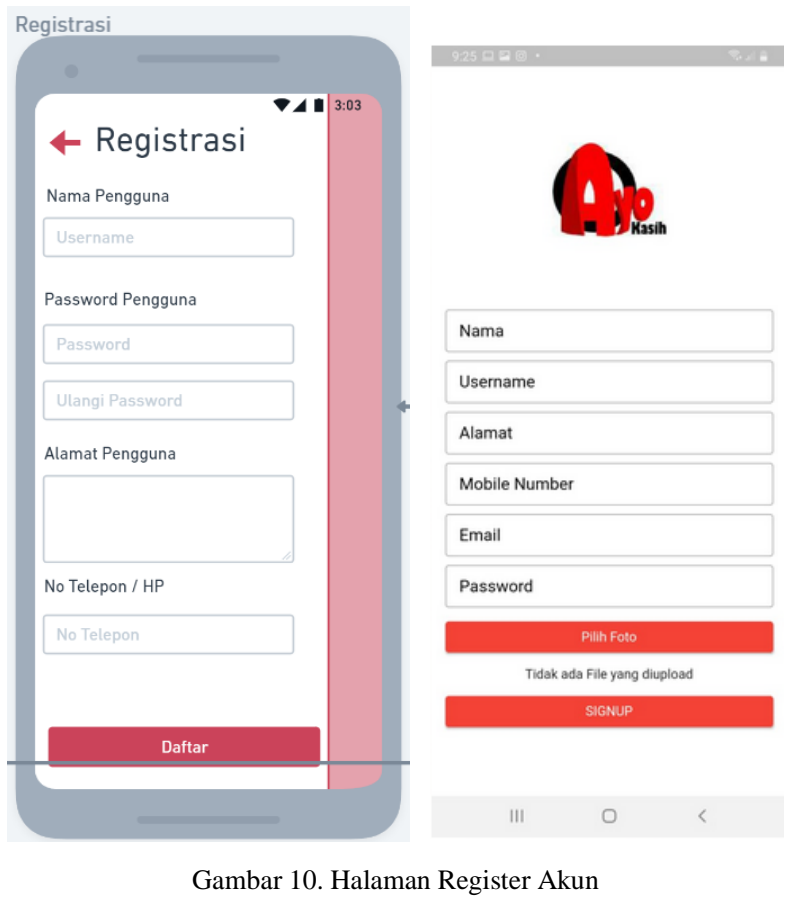


Gambar 10 merupakan halaman register akun untuk pengguna yang belum memiliki akun. Pengguna harus mengisi data nama pengguna, password pengguna, alamat pengguna, dan no telepon/HP untuk melakukan pendaftaran.

Setelah melakukan registrasi, pengguna dapat langsung masuk ke halaman utama seperti gambar 11.

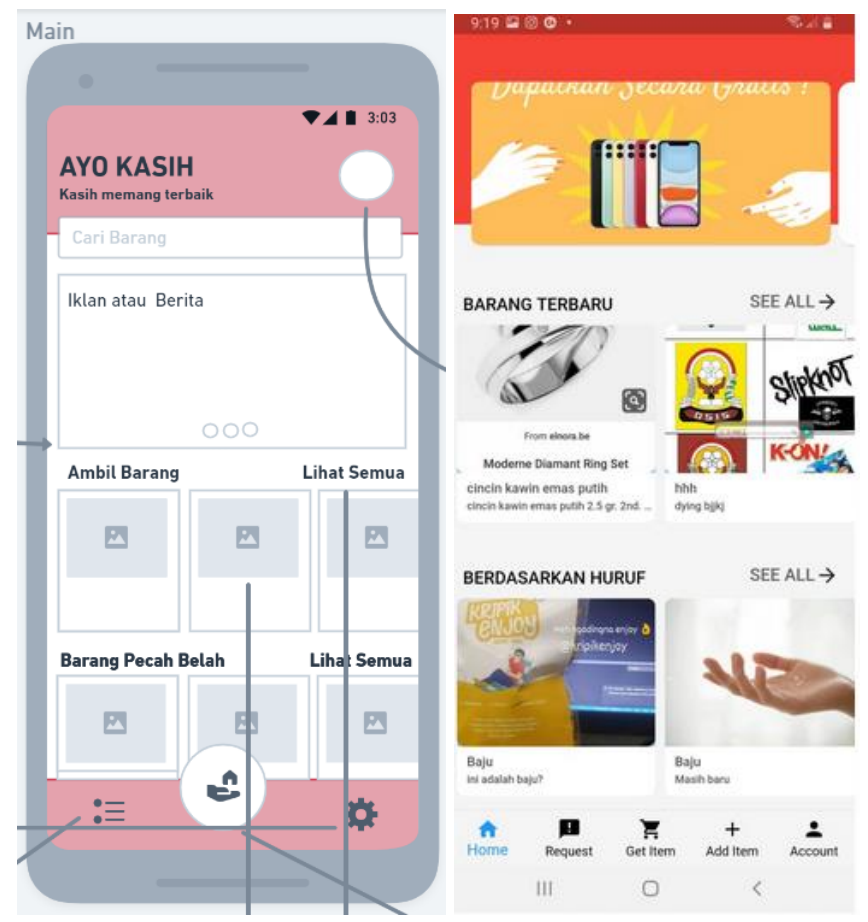

Gambar 11. Halaman Utama

\section{B. Tampilan Transaksi Kasih dan Terima}

Pada tampilan ini pengguna dapat masuk ke beberapa menu yaitu seperti List Barang, Kasih Barang, Terima Barang, dan Profile. Penjelasan untuk masing-masing menu akan dijelaskan pada gambar 12. List Barang, menuju tampilan halaman barang-barang yang akan ditawarkan.

Pada tampilan juga dapat terlihat dibagian besar terdapat tempat untuk berita terbaru juga sebuah textfield untuk mencari barang. Terdapat juga pembagian barang barang berdasarkan kategori kategori yang sudah tersedia sebelumnya.

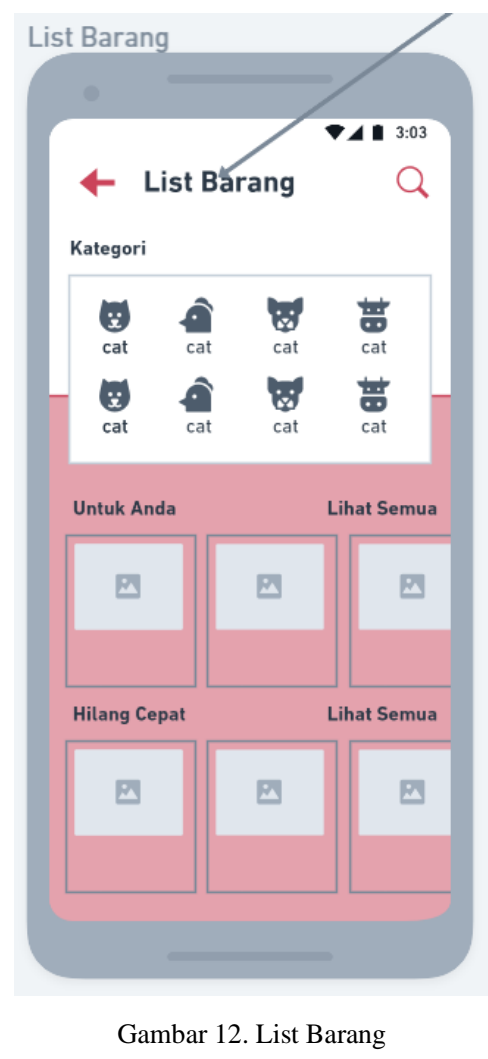

Pada tampilan List barang, pengguna dapat melihat deskripsi dari barang dengan meng-klik gambar dari barang tersebut. Tampilan deskripsi detil barang akan muncul seperti gambar 13 .

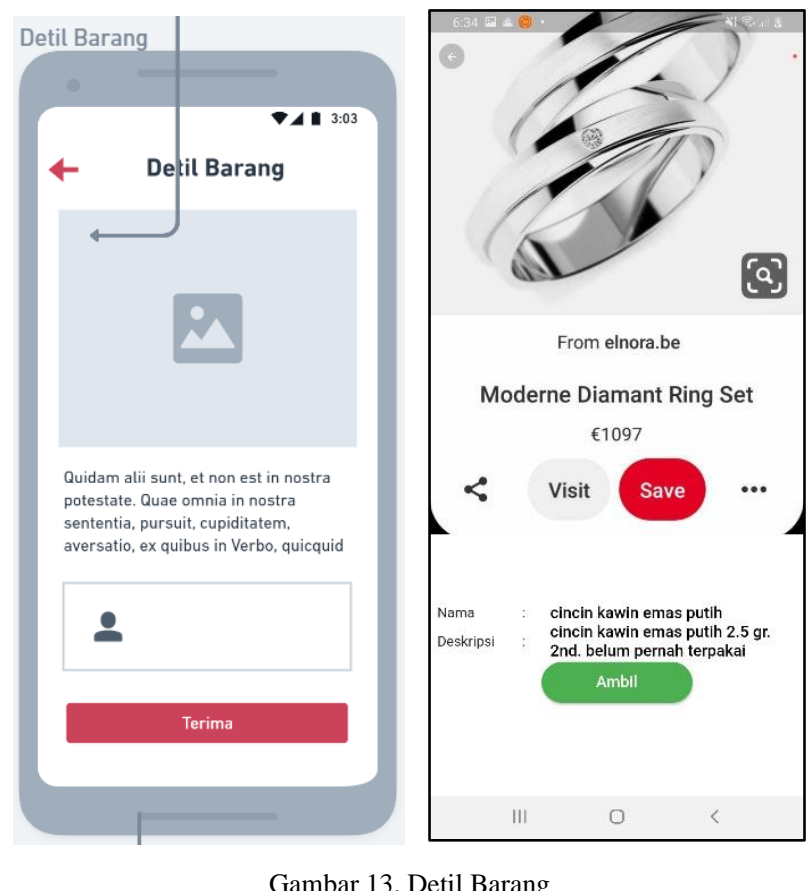

Gambar 13. Detil Barang 
Pengguna yang hendak menawarkan barang yang akan diberikan dapat mengisi pada menu Kasih. Berikut tampilan gambar (Gambar 14) bagi pengguna yang akan input barang. Keterangan yang harus diisi adalah foto barang dan detil barang.
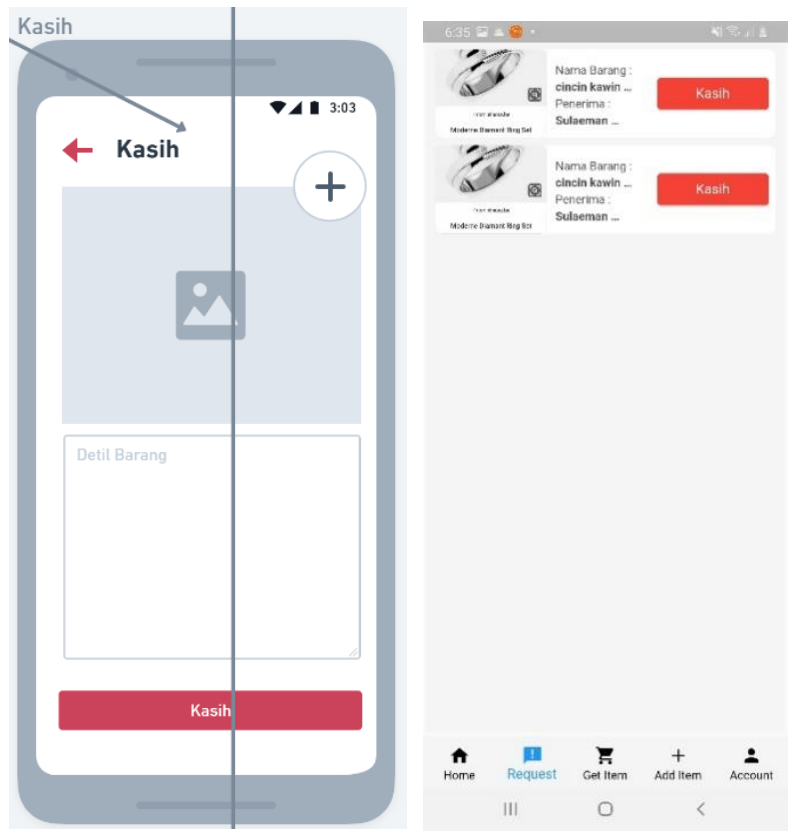

Gambar 14. Tampilan Kasih Barang

Gambar 15 merupakan tampilan dari sisi pengguna yang mengambil barang yang ditawarkan. Pengguna harus mengisi waktu pengambilan dan metode pengambilan. Status dari pengambilan yaitu menunggu konfirmasi, menunggu barang dikirim, dan konfirmasi kiriman.
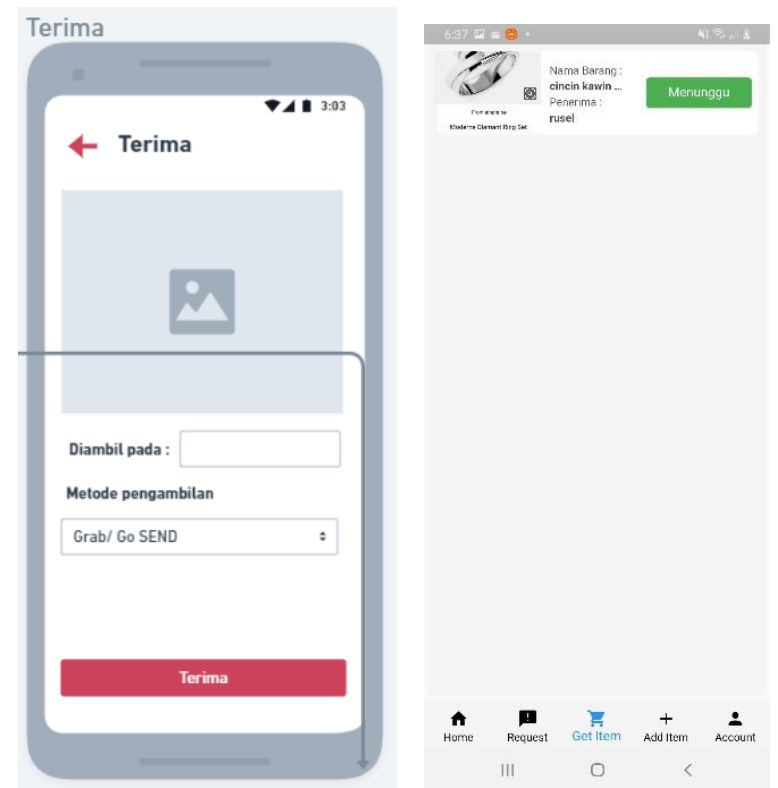

Gambar 15. Tampilan Terima Barang
Tombol pada user interface akan berubah sesuai dengan status barang/ transaksi yang terjadi pada saat ini (Gambar 16).

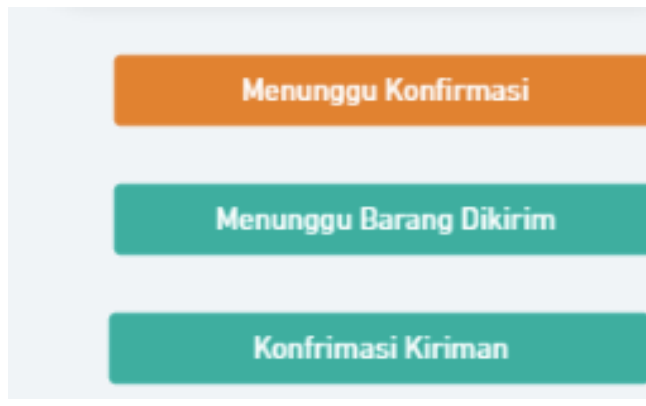

Gambar 16 Perubahan warna tombol

Profile pengguna, menuju ke halaman data diri pengguna. Pada profile pengguna tersimpan foto, nama, no telp, alamat. Selain itu pada profile pengguna dapat melihat barang terima, barang kasih, dan sejarah transaksi (Gambar 17).

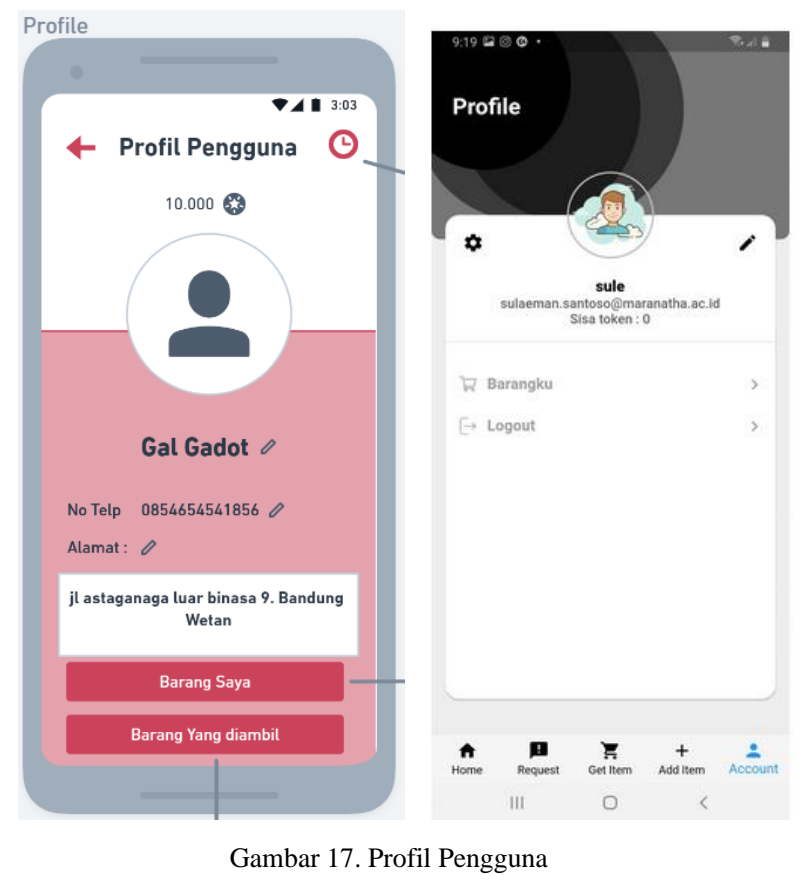

Gambar 18 menunjukkan tampilan untuk semua barang yang dimiliki / sudah diunggah oleh user. Disini user juga dapat melihat detil tiap tiap barang . 


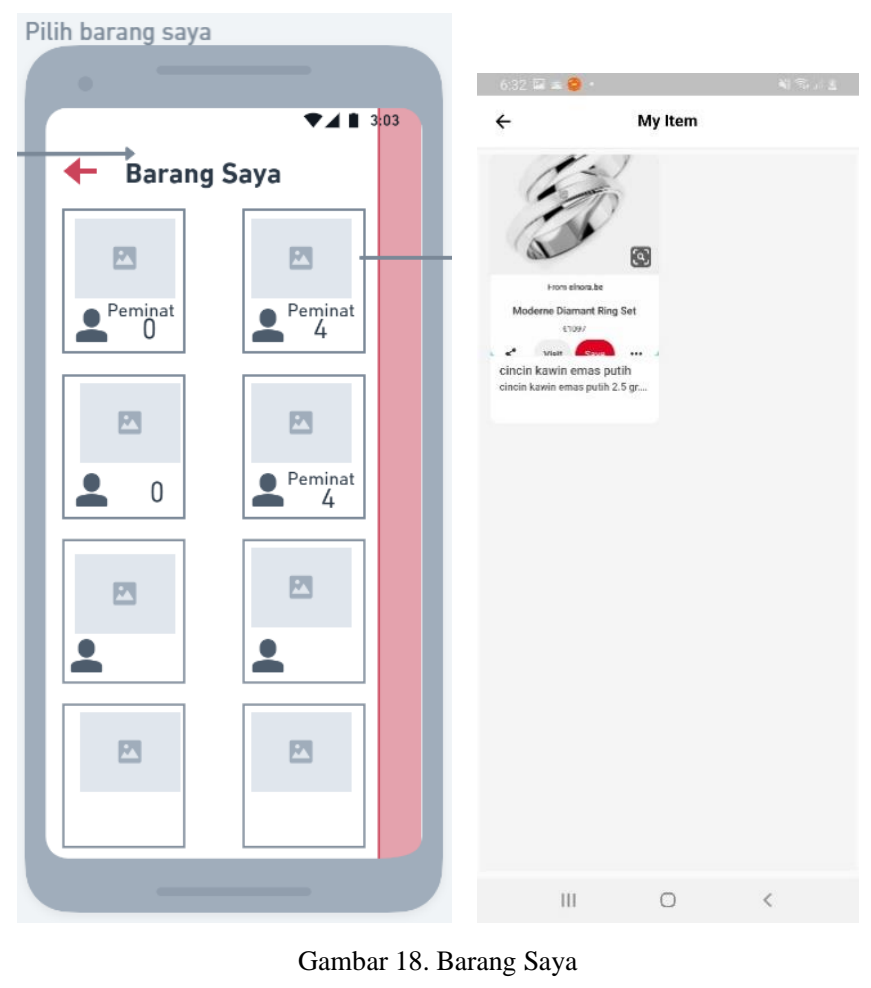

Gambar 19 merupakan tampilan barang-barang yang ditawarkan oleh pengguna dengan jumlah peminat dari masing-masing barang. Pengguna selanjutnya dapat menentukan kepada siapa barang yang ditawarkan akan diberikan, berikut tampilannya

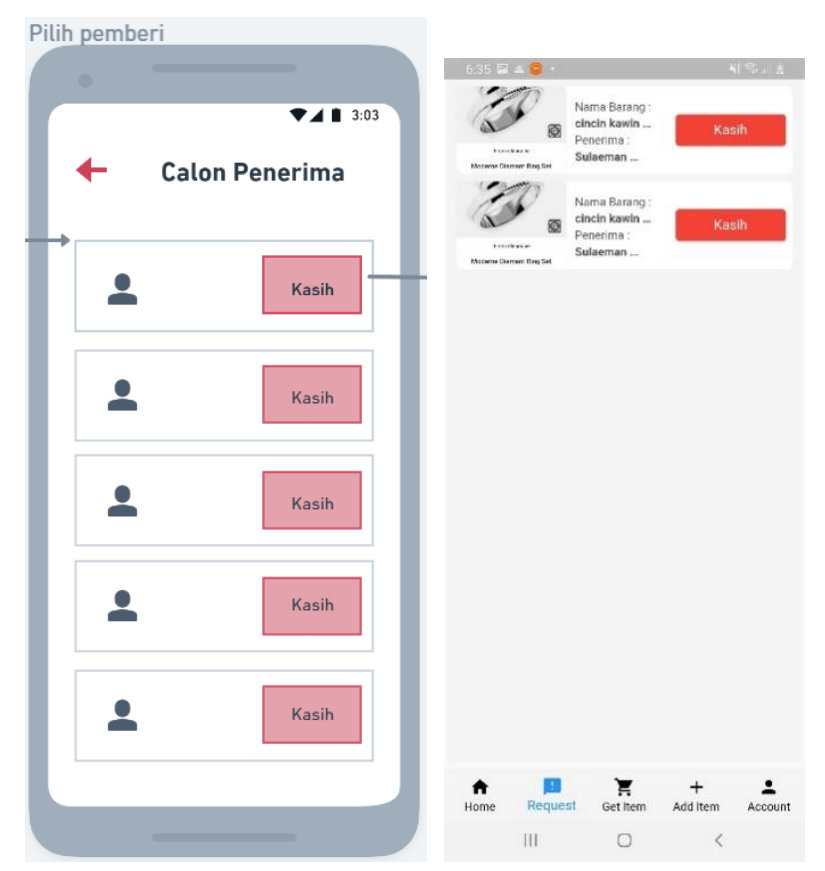

Gambar 19. Calon Penerima
Gambar 20 adalah proses akhir pengguna yang akan memberikan atau membatalkan barang yang sudah diminati oleh pengguna lain.

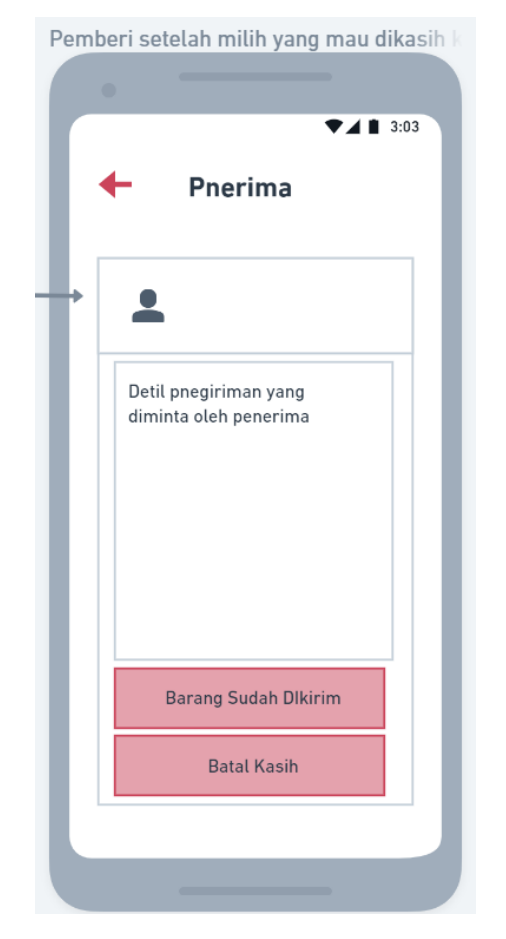

Gambar 20. Tampilan Persetujuan Pemberi

Untuk setiap transaksi yang dilakukan baik kasih maupun terima, pengguna dapat melihat sejarah transaksi semua barang yang sudah dilakukan. Gambar 21 merupakan tampilan dari sejarah transaksi.

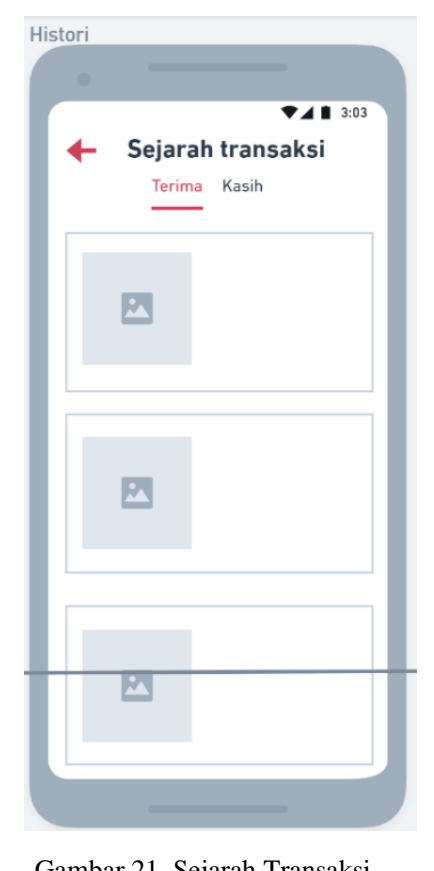

Gambar 21. Sejarah Transaksi 


\section{KESIMPULAN}

\section{A. Simpulan}

Dari hasil penelitian tersebut dapat diambil kesimpulan bahwa sistem tukar barang untuk pemanfaatan barang tidak terpakai ini dapat memberikan informasi kepada masyarakat tempat melakukan dan mengakomodasi pertukaran barang user secara online. Sistem ini juga sudah menyediakan sistem token namun pada saat ini sistem ini belum ditampilkan karena belum sesuai dengan kebutuhan sistem, namun akan tersedia untuk perkembangan sistem lebih lanjut.

\section{B. Saran}

Aplikasi ini sudah mengakomodir pertukaran barang namun tidak terhubung dengan sistem pengiriman barang sehingga akan sangat baik untuk perkembangan ke depan agar aplikasi ini terhubung dengan sistem pengiriman yang sudah tersedia ( $3^{\text {rd }}$ party). Penggunaan sistem token pada saat ini belum dievaluasi dan untuk rencana kedepan penggunaan sistem ini dapat dievaluasi keuntungan atau kekurangannya. Aplikasi ini juga masih memiliki kekurangan pada sistem pencarian berdasarkan kategori atau filtering lanjut yang diperlukan

\section{UCAPAN TERIMA KASIH}

Ucapan terima kasih kepada LPPM Universitas Kristen Maranatha yang sudah memberikan dukungan dalam penelitian ini.

\section{DAFTAR PUSTAKA}

[1] K. Anderson. (2020) Mint. [Online]. Tersedia: https://www.mint.com/barter-system-history-the-past-andpresent.

[2] P. Abraham, "Agent based E-barter system," International Journal of Advance Research in Computer Science and Management Studies, vol. 5, pp. 85-88, Mei 2017.

[3] Y. E. Cakmaz, F. O. Alaca, C. Durmaz, B. Akdal, B. Tezel, M. Challenger dan G. Kerdas, "Engineering a BDI Agent-based Semantic e-Barter System," UBMK 2nd International Conference on Computer Science and Engineering, 2017, pp. 1072.

[4] K. Saito, "Maintaining Trust in Peer-to-Peer Barter Relationship", International Symposium on Applicaton and the internet workshop, vol. 1, pp. 582, 2004.

[5] J. Huo dan H. Qu, "Design and implementation of a secondhand items trading platform based on Android," ICCSNT, Lanzhou, 2016, pp. 21-25.

[6] Z. Hai-tao, "Campus Second-hand Goods Trading Platform Design based on B/S," International Conference on Intelligent Computation Technology and Automation, Hebei, 2015, pp. 1255-1260.

[7] M. Bravetti, A. Casalboni, M. Nunez dan I. Rodiguez, "From Theoretical e-barter Models to an Implementation Based on Web Services," Electronic Notes in Theoretical Computer Science, vol. 159, pp. 241-264, 2006.

[8] S. Nishioka, Y. Yaguchi, T. Hamada, M. Onizuka dan M. Yamamuro, "XML-Based e-Barter System for Circular Supply Exchange," International Conference on Database and Expert Systems Applications, Berlin, 2005, pp. 461-470.

[9] Google. (2020) Flutter dev. [Online]. Tersedia: https://flutter.dev/

[10] W. Leler. (2020) "hackernoon,”.[Online]. Tersedia: https://hackernoon.com/whats-revolutionary-about-flutter$946915 b 09514$.

[11] T. Otwell, (2020) "Laravel website," [Online]. Tersedia: https://laravel.com/.

[12] Laravel LLC. (2020) "Laravel Documentation,"[Online]. Tersedia : https://laravel.com/docs/8.x/ 